\title{
A convivência e o com-viver como dispositivos para a Terapia Ocupacional
}

\author{
Sabrina Helena Ferigato, Carla Regina Silva, Gerusa Ferreira Lourenço
}

Departamento de Terapia Ocupacional, Universidade Federal de São Carlos - UFSCar, São Carlos, SP, Brasil.

\begin{abstract}
Resumo: Objetivo: A convivência e os processos de com-viver são os temas deste trabalho, com o objetivo de refletir sobre a convivência como um dispositivo para a terapia ocupacional em diferentes campos de sua atuação profissional, explorando seus desafios e possibilidades. Método: Trata-se de uma reflexão teórica, na qual são apresentados brevemente os conceitos de convivência e dispositivo, para, posteriormente pensar sua interface com a profissão. Para refletirmos sobre essa temática, recorremos aos teóricos do campo da Filosofia da Diferença, além de intercessores do núcleo da terapia ocupacional. Resultados: Como resultados da reflexão, podemos apontar que os encontros são essencialmente ético-afetivos e que consideramos que os espaços propiciadores da convivência com o outro, onde possam ser acolhidas as diferenças e as potencialidades do devir minoritário de indivíduos e grupos, são essenciais para as práticas terapêutico-ocupacionais e para a valorização da dimensão da experiência. Nesse contexto, o sujeito da experiência se definiria não apenas por sua atividade, mas por sua receptividade, por sua disponibilidade, e por sua abertura para relacionar-se com o outro, para a experimentação do mundo e de si. Conclusão: Nesta perspectiva, consideram-se a convivência e o com-viver como dispositivos para a terapia ocupacional, que se entrelaçam na criação de espaços de relação e de produção de existência na potência e em devir.
\end{abstract}

Palavras-chave: Terapia Ocupacional, Socialização, Prática de Grupo, Estratégias.

\section{The conviviality and the live-with as Occupational Therapy devices}

\begin{abstract}
Objective: The conviviality and the live-with process are the subjects of this work, with the purpose to reflect about living as an occupational therapy tool exploring its challenges and possibilities in its different fields. Method: Theoretical reflection in which the concepts of conviviality and tool are briefly presented, to then think about its interface with the profession. To discuss the subject, we sought specialists in the field of Philosophy of Difference, in addition to occupational therapy core intercessors. Results: As a result of the reflections we can state that the meetings are essentially ethical-affective; we consider essential the spaces that embrace differences and the individuals and groups potential of becoming minority for therapeutic-occupational practices and to the enhancement of the experience dimension. In this context, the experiment subject will be defined not only for his/her activity, but by his/her receptivity, willingness and openness to relate with the other, for experiencing the world and himself/herself. Conclusion: This perspective considers the conviviality and the live-with as occupational therapy tools, which are related in the creation of spaces of relation and the creation of becoming existence.
\end{abstract}

Keywords: Occupational Therapy, Socialization, Group Practice, Strategies.

Autor para correspondência: Sabrina Helena Ferigato, Laboratório Atividades Humanas e Terapia Ocupacional, Departamento de Terapia Ocupacional, Universidade Federal de São Carlos, Rodovia Washington Luís, Km 235, SP 310, São Carlos, SP, Brasil, e-mail: sabrinaferigato@gmail.com 


\section{Introdução}

Este ensaio busca refletir sobre as possíveis correlaçôes entre a noção teórica de convivência e as intervençôes em terapia ocupacional, uma vez que esta estratégia está implicada no trabalho do terapeuta ocupacional; além disso, busca explorar de que maneira as vivências de convívio e os processos de conviver podem funcionar como dispositivos $\mathrm{da}$ nossa prática profissional.

Para Foucault (1992), todo dispositivo inclui um conjunto heterogêneo que engloba discursos, instituiçôes, organizaçóes arquitetônicas, decisóes regulamentares, leis, medidas administrativas, enunciados e proposições filosóficas e morais. O dispositivo é a rede que se pode estabelecer entre estes elementos. Para Deleuze (1996), a partir de sua releitura de Foucault, um dispositivo é, antes de qualquer coisa, um conjunto multilinear composto de linhas de natureza diferente: linhas de visibilidade e de enunciação (máquinas de fazer ver e falar), além das linhas de força e de subjetivação (que comportam as dimensóes do poder e da criação).

Para discutirmos a convivência como um dispositivo, fez-se necessário um mergulho sobre o tema e seus correlatos, bem como sua contextualização e articulaçáo com a terapia ocupacional, a partir do referencial da Filosofia da Diferença (FERIGATO, 2013).

É importante esclarecer que as práticas de convivência, embora não explicitamente enunciadas, já vêm sendo campo fértil para a construção de conhecimento em terapia ocupacional, bem como um importante instrumento para o fortalecimento das políticas públicas. Dentre estas, citamos o SUS (Sistema Único de Saúde) e o SUAS (Sistema Único de Assistência Social), as políticas no campo da Educação e da Cultura, entre outros, especialmente quando pensamos na criaçáo de espaços coletivos para a construçáo e o fortalecimento de redes de atenção, de suporte pessoal e social, de proteção social, de sociabilidades, de colaboração criativa e/ou de cocriação.

Além disso, em um contexto neoliberal de produção de coletivos amedrontados, desigualdades sociais, desinvestimentos nos espaços públicos e desapropriação do comum, o trabalho pela convivência segue na contramão, em uma aposta de investimento em estratégias que resgatem a capacidade de iniciativa política por diferentes grupos sociais, pela restauração no plano micropolítico dos laços sociais enfraquecidos e na produção de redes afetivas (TEIXEIRA, 2004).
Neste contexto, propomos pensar as práticas da terapia ocupacional com enfoque em produção de espaços de convivência, em sua possibilidade de funcionar como acontecimentos que reinauguram processos coletivos, subjetivos e sensíveis, e, ao mesmo tempo, resgatam o próprio coletivo, podendo operar a sua produção como plano de criação (ESCÓSSIA; TEDESCO, 2009).

No campo das práticas intersetoriais, ou seja, aquelas que se correlacionam com distintos campos e saberes de práticas, entendemos que alguns dispositivos podem operar como autênticas técnicas de reconstituição e de produção do laço social (TEIXEIRA, 2004). Espaços, como ateliês, oficinas, práticas de intervençấo na cidade, centros de convivência e outras experiências comunitárias, podem criar instâncias locais de subjetivação coletiva (GUATTARI, 2006), intercruzando diferentes saberes, práticas e experiências.

\section{A Convivência e o Com-viver}

Poucos são os estudos que se destinaram especificamente a trabalhar conceitualmente o termo convivência. No entanto, não são raros estudos antropológicos, psicológicos e filosóficos que problematizam os modos de convívio a partir do esforço de produzir conhecimento sobre as diferentes formas de produção de relaçôes sociais e da vida em sociedade.

$\mathrm{Na}$ antropologia, pesquisadores se dedicam a compreender a forma de convivência de diferentes povos em todo o mundo, a entender como é possível que o mundo continue a criar-se e recriar-se sem cessar, em meio à diversidade de culturas e de estruturas sociais, produzindo diferentes formas de subjetividade individual e coletiva (MARTORELL, 1997).

Na psicologia, diferentes abordagens teóricas se dispóem a pensar a produção subjetiva e a constituição de sujeitos a partir da análise das relaçóes interpessoais e do evento da civilizaçáo.

Tomando-se por base as construçóes teóricas de Vygotsky, o Ministério do Desenvolvimento Social e Combate à Fome - MDS, em sua cartilha sobre concepção de convivência e fortalecimento de vínculos, afirma que o mundo e a atuação sobre este é possível somente por meio de relaçôes sociais, ou seja:

O sujeito se constitui na relação com o outro e passa a dispor, por meio dessa relação, das conexóes estabelecidas por outras pessoas tendo-as também como referência e contribuição para o coletivo. Assim, são 
relevantes as formas de intervenção que promovem encontros que afetam as pessoas, mobilizando-as e provocando transformaçóes. No mesmo sentido, é importante destacar a relevância do contexto histórico nessa construção, pois as condiçóes objetivas da vida interferem diretamente na forma como as pessoas se constituirâo como sujeitos sociais, nas escolhas que farão ao produzir e reproduzir a vida social (BRASIL, 2013a, p. 17).

Esse modo de perceber as relações sociais tem fortes influências do pensamento de Spinoza, que, a partir do campo filosófico, nos ajuda a entender as relaçóes sociais e a própria vida a partir do conceito de "encontro". A vida inclui a sinergia coletiva e a cooperação social e subjetiva. Vida significa afeto, inteligência, cooperação, desejo - poder de afetar e ser afetado (SPINOZA, 2008).

A noção spinozana de encontro nos leva a identificar que a natureza dos encontros não é, por si só, positiva, nem negativa. Para ele, os encontros são essencialmente ético-afetivos, vinculados à noçâo de composição ou de decomposição na relação entre os corpos ${ }^{1}$, na imanência da própria experiência. Um bom encontro é caracterizado pela composição, pelo aumento da potência de um corpo, e um mau encontro, pela decomposição ou pela diminuição da potência de agir ou da força de existir de um corpo relacional (SPINOZA, 2008).

Quando Spinoza (2008) propóe que um corpo é essencialmente relacional, significa que um corpo não está e nunca estará completamente formado, uma vez que ele é permanentemente afetado pelo mundo do qual é parte e que também está em constante transformação e geração. Ou seja, os encontros transformam a instável forma-corpo e, quanto maior é a capacidade de composição de um corpo, maior sua potência de perseverar na existência.

Em diferentes políticas públicas, a palavra "convivência" carrega em si outras noçôes, que, a partir do imaginário e na experiência dos profissionais, estão ligadas ao efeito de conviver (INFOPÉDIA, 2015), tais como: inclusão social, criação de vínculos, redes de apoio, criação de laços sociais, relaçôes interpessoais, direitos dos usuários, produção de subjetividade, entre outros (BRASIL, 2011a, 2011b, 2013b).

Esse efeito de conviver só é possível a partir da experiência de viver com: com-viver com o outro, estar com o outro, que é sempre mais ou menos diferente de mim, esse é um passo essencial para a produção de convivência. Esse passo nem sempre é fácil, mas é fundamental. Por isso, optamos por ressaltar no título desse manuscrito a decupagem ortográfica do verbo conviver para "com-viver", na tentativa de enfatizar a composição dessas palavras (da preposição conectiva com e o verbo viver). Gostaríamos de dar destaque ao elemento "com" como um antepositivo que reforça o sentido do verbo "viver", como um viver a partir do encontro. As preposições são palavras que estabelecem uma relação entre dois ou mais termos da oração, uma preposição como essa cumpre a função de ligar elementos: no caso das oraçôes, ligar palavras; no caso da convivência, ligar também sujeitos individuais e coletivos.

Podemos afirmar, em concordância com Deleuze e Guattari (1995, p. 16), que “[...] não existe um modelo de convivência ideal, como não existe uma comunidade homogênea. A convivência é uma realidade essencialmente heterogênea [...]" e marcada pela produção de diferenças.

A convivência delineada nesta perspectiva - entre sujeitos que se constituem na medida em que se relacionam, sujeitos capazes de escolha, de autonomia e de aprenderem entre si (BRASIL, 2013a), acontece, sob uma perspectiva compartilhada entre diferentes campos de saberes. No entanto, o exercício da convivência também se impóe em situaçóes menos favorecidas, quando, por exemplo, os direitos nem sempre são garantidos e a autonomia das pessoas é comprometida por questóes de ordem física, social, cognitiva ou psíquica.

Tradicionalmente, as populaçôes atendidas pelo terapeuta ocupacional, como as pessoas com deficiências, em sofrimento psíquico ou em situação de vulnerabilidade social, idosos, entre outras, são exemplos de condiçóes nas quais as convivências de forma potencializadora para os processos e projetos de vida estão cerceadas, e podem ser experimentadas junto às múltiplas formas de exclusão (econômica, social, cultural, ocupacional, etc...). Em casos como estes, a convivência pode ser também atravessada por esses mesmos processos de exclusão, assujeitamentos e estigmas. E é especialmente nesses contextos que procuraremos abordar a interface entre os processos de convívio e a terapia ocupacional.

\section{A Convivência e a Terapia Ocupacional: Correlações Possíveis}

A partir das construçôes teóricas que traçamos, podemos entender que conviver é também um modo de existir na relação com os outros, com pessoas, pensamentos, ambientes e coisas. Nesse sentido, há um ethos convivencial, que se diferencia 
de uma pessoa para outra. Entendendo ethos, em seu sentido grego:

Uma atitude [...] uma maneira de relacionar-se com a realidade atual [...] e finalmente uma maneira de pensar e de sentir; uma forma de atuar e conduzir-se que ao mesmo tempo marca a relação de pertinência e de apresentação de si mesma (FOUCAULT, 1984, p. 295).

Esse modo de nos relacionarmos é definido, entre outras coisas, pelas marcas que produzimos, ao longo de nossa história, no encontro com outras marcas, por nossas potencialidades e limitaçôes no encontro com as potencialidades e limitaçóes de outros corpos e materialidades. Essas potências e esses limites são convidados a expressar-se no ato de conviver.

Não é raro terapeutas ocupacionais serem procurados por pessoas "marcadas" por diferentes limitaçóes (concretas e subjetivas), para apoiá-las na construção de possíveis estratégias de convivência (MEDEIROS, 2010). Intervir junto a essas limitaçóes é uma das grandes contribuiçôes da terapia ocupacional e a maior parte das construçóes teóricas da profissão nos ajudou a identificar e desenvolver técnicas para intervir nessas dificuldades ocupacionais e cotidianas. No entanto, o maior desafio está em ir para além disso e identificar diferentes modalidades de intervenção a partir das potências convivenciais de cada sujeito individual e coletivo e não apenas a partir de suas limitaçóes.

Segundo definição da Universidade de São Paulo, a terapia ocupacional é uma profissão que realiza sua intervenção no âmbito da saúde, do trabalho e da educação, e na esfera social, a qual reúne:

Tecnologias orientadas para a independência e autonomia de indivíduos que por diversas problemáticas ligadas a fatores físicos, sensoriais, mentais, psicológicos e/ou sociais demonstram dificuldade na inserção e participação na vida social [...] (UNIVERSIDADE..., 1997).

Um dos principais objetivos da terapia ocupacional seria a inserção social de sujeitos individuais e coletivos por meio da ação no seu cotidiano.

O cotidiano é o espaço no qual a vida acontece, permeado de relações políticas, econômicas e sociais que o atravessam. As açôes realizadas nos cotidianos são denominadas por meio de diferentes terminologias, tendo em vista sua aplicação no campo da terapia ocupacional: fazer, atividade, ocupação, etc, com base em referenciais teóricos distintos (MAGALHÁES, 2013; LIMA; OKUMA; PASTORE, 2013; GALHEIGO, 2003).

Entre diferentes autores, se

[...] reconhece a polissemia, a polivocidade e a pluralidade inevitável para a construção de um campo que foi, necessariamente, marcado por práticas e saberes diversos [...] (SILVA, 2013, p. 462).

Já o termo atividade humana é compreendido como a essência do ser humano; por meio desta, o indivíduo se cria e se recria, produzindo sentidos de vida na sua práxis, no seu fazer (FURTADO; MARCONDES, 2013), nas múltiplas dimensões que constitui a vida, num continuum experiencial em que se produzem verdades (QUARENTEI, 2001).

A atividade humana é um objeto polissêmico, complexo e pertencente a todos, que necessariamente se mantém em relação com os demais corpos. Ela nâo é propriedade de um núcleo profissional, no entanto, é inegável que a terapia ocupacional se dedica em profundidade ao conhecimento e às práticas voltadas para o tema da atividade humana.

Do mesmo modo, a convivência integra a experiência humana de forma a interconectar pessoas, fazeres e suas complexidades. Por isso, unindo esses universos, afirmamos que a convivência pode ser pensada como um dispositivo importante para a terapia ocupacional, caracterizando-se como mais do que um recurso terapêutico-ocupacional ou um instrumento de intervenção.

Termos, como:

Instrumento ou recurso começam a ser utilizados para qualificar as atividades em terapia ocupacional. Assim, os terapeutas ocupacionais realizam uma discriminação entre atividade e seu possível caráter terapêutico, superando o reducionismo que acompanhava a ideia de que as atividades trazem em si propriedades terapêuticas (LIMA; OKUMA; PASTORE, 2013, p. 245).

O termo recurso ou instrumento remete à ideia de um meio para atingir determinados objetivos. A noção de dispositivo, por outro lado, parte do pressuposto do que a convivência em si produz coisas - encontros, enunciados, relaçóes de poder e movimentos de subjetivação - que já são a finalidade à qual a terapia ocupacional se propóe.

Conviver é, a partir desse referencial, experimentar um tempo compartilhado. Pessoas convivem e compartilham a ocupação de seu tempo em diferentes espaços e em diferentes circunstâncias de vida. Ao pensar a convivência como um dispositivo de 
intervenção em terapia ocupacional, temos que nos atentar ao que tornaria esse dispositivo mais eficaz para os propósitos de inserção social e ampliação da vida ocupacional e relacional de sujeitos e coletivos. E, nesse caso, seria insuficiente pensarmos a ocupação ${ }^{2}$ e a convivência apenas em termos de uso e compartilhamento do tempo.

Faz-se necessário pensarmos também estratégias e modos singulares de ocupaçáo dos espaços, e de sobremaneira, a ocupaçáo dos espaços públicos ou a ocupação de espaços coletivos de convívio, em outros termos, por meio da produçáo de zonas de comunidade, a produção do comum.

O comum não se refere a noçôes tradicionais da comunidade ou do público; baseia-se na comunicação entre singularidades e se manifesta através dos processos sociais colaborativos de produção (HARDT; NEGRI, 2012, p. 266).

\section{A Convivência como um Dispositivo para a Terapia Ocupacional}

Para além de um meio, a convivência como acontecimento produz uma intervenção: estar junto, produzir um laço, com-viver. $\mathrm{E}$ isso é parte do que se busca. Daí, a noção de dispositivo: a convivência pode produzir encontros, dar relevo à produção subjetiva, evidenciar enunciados, relaçôes de poder e de saber.

Isso não significa negar a importância e a necessidade do desenvolvimento de recursos e instrumentos de intervenção. Parte-se do princípio de que prioritariamente não nos interessa a convivência como estado de coisa, nem como uma técnica em si para o trabalho de terapeutas ocupacionais. Os processos que produzem a convivência e são nela produzidos é o que nos interessa.

Por exemplo: a promoção de situaçôes de convivência inclusiva para determinada população, em um dado território, produz, a um só tempo, parte do que buscamos atingir, que é o convívio social para pessoas que tenham limitaçôes, que é construir essa experiência autonomamente, por diferentes construçôes de si, do outro e do entorno dessa relação. Entretanto, também evidencia um conjunto de elementos importantes para a intervenção do terapeuta ocupacional, tais como: as relaçóes de poder, de saber e de produção de subjetividade daquela população; a dinâmica do território; as singularidades de cada sujeito em composição com um grupo; as estratégias já vivas ou a serem criadas para a superação de obstáculos; a criação de novas formas de relação, etc.

Apostamos na convivência em sua potencialidade de funcionar como um catalizador para processos de transformação, de mudanças (FERIGATO, 2007), como um solo de subjetivação (WEINMANN, 2006) ou como um dispositivo para a potencializaçáo da vida ocupacional, como uma atividade humana em ato.

De acordo com Foucault (1992), o trabalho como ato, atividade, possui as funçóes: produtiva, simbólica e de adestramento ou disciplinar; o indivíduo trabalha pela necessidade de criar, inventar antecipadamente o mundo, que seria sua fé na verdade, que leva o sujeito a desejar fixar relaçóes que tenham sempre um grau e uma força para transformar-se em luta diária, na qual qualquer impedimento se torna estressante, fator de crise, de diminuição da autoestima, entre outros. Nesse contexto,

[...] resgatar a autonomia é fazer com que o desejo em ser aflore em nós, a partir da força da luta interna. Precisamos usar a força para alcançarmos a autonomia, estabelecendo, com isso, uma relação de recaptare [...] (FURTADO; MARCONDES, 2013, p. 654).

Nesse sentido, produzir convivência, cena em que diferentes pessoas se disponham a com-viver, pode vir a ser um dispositivo para a terapia ocupacional, um modo de colocar diferentes elementos em relaçáo, discursos, modos de produção de vida, intermediados por atividades e momentos de criação, produzindo mudanças.

Para Ferreira e Oliver (2010), as experiências da convivência diária possibilitam ao indivíduo transitar por diferentes espaços sociais, o deslocamento de si para o desconhecido, para os sentimentos de prazer e dificuldades da vida coletiva, estabelecendo conexóes, compartilhando determinados valores e novas maneiras de viver e de se expressar. Ou seja, permite a diminuição das situações de isolamento e a inclusão em um conjunto.

A convivência como um dispositivo da terapia ocupacional permite mobilizar a vida em circunstâncias diversas em que ela pede mobilidades desviantes, "[...] um devir diferencial que se sente por um calor nas relações, por uma afirmação positiva da criatividade [...]" (GUATTARI; ROLNIK, 1986, p. 47). Afinal, a proliferação de diferenças, definindo as infinitas formas de ser, e a crescente força de homogeneização, buscam estabelecer as bases de um modo de existência único (LIMA, 2003). Criar espaços de relação e de produção de existência na potência pelo devir são 
práticas lapidadas por terapeutas ocupacionais em espaços de convivência.

Trata-se, portanto, de produzir processos de experimentação, aceitando o desafio de afirmar o corpo-em-devir ${ }^{3}$, em resistência, e, ao mesmo tempo, negar o corpo normativo, adaptado, estratificado, disciplinado, passivo, buscando colocar esse corpo disciplinado em relação com experiências inéditas, em linhas de fuga e campos de intensidade (FERRACINI et al., 2014).

De acordo com Eichelberger (2012), mobilizar a vida passa por se pensar em dispositivos que, em sua constituiçáo, funcionamento e uso, produzam potência de ação coletiva, potência essa que é definida por um plano de relações possíveis. É nessa perspectiva que pensamos a relação entre terapia ocupacional e convivência.

O que caracteriza um dispositivo nesse contexto terapêutico-ocupacional é sua potência de irrupção daquilo que se encontra bloqueado, sua potencialidade de fazer ver e falar o que se apresenta e o não explícito, o dito e o não dito.

Se a vida cotidiana é um objeto importante para a terapia ocupacional, sabemos que, ao lado dos objetos com seus contornos estáveis, existe um plano coletivo de forças que os produzem, um plano movente da realidade das coisas que não pode ser abandonado quando se pretende compreender um objeto (ESCÓSSIA; TEDESCO, 2009).

Nesse sentido, articular intervenção terapêutica ocupacional com estratégias de convivência pode propiciar maiores possibilidades de não isolarmos nosso objeto de intervenção de suas articulaçóes históricas e de suas conexôes com o mundo. Para isso, é preciso dar conta de suas modulaçóes e de seus movimentos permanentes. A convivência propicia, em grande medida, esses movimentos, de potencialização e despotencialização. É preciso acompanhar esses processos, estar atento às brechas que produzem intervençóes possíveis.

Considerar o encontro como topos de engendramento de espaço-tempo, através da imprevisibilidade do devir que o percorre, e forja superfícies efetivas e perceptivas inéditas. Tomar o encontro como acontecimento, neste sentido de transformaçáo de percepçóes e sensibilidades, e leva-lo às consequências mais extremas, buscando não nos acomodarmos em um plano de trocas, envios e recebimento de elementos sensíveis ou de saber dados a priori (LIMA; ARAGON, 2010, p. 140).

A produçáo de momentos de convivência ativa também produz um deslocamento do terapeuta ocupacional, que se desloca do lugar construído hegemonicamente em settings protegidos e referenciais teóricos aplicados. Ao com-viver, nos vemos diante de uma possibilidade de tecer territórios existenciais na contramão da serialização da saúde ortodoxa, da educação disciplinar ou de políticas normativas hegemônicas (PELBART, 2003).

O terapeuta ocupacional é convidado à imersão em um contexto específico e complexo, imersão como [...] disponibilidade, um engolfamento, um mergulho e, se bobear, um afogamento. Trata-se de um modo de perceber/sentir um determinado espaço/ tempo casual ou produzido voluntariamente [...] (BORGES; ETLIN, 2010, p. 94).

Assim, numa postura de receptividade afetiva, encarnada nas situaçóes reais, nos permitimos falar "com" e não apenas falar "sobre" ou "para" um objeto (ALVAREZ; PASSOS, 2009).

A convivência é fruto de uma relação que se produz artesanalmente. A matéria-prima dessa relação artesanal são as pessoas, a vida humana e suas experiências, que, através do convívio, se transforma num produto vivido e compartilhável. Nesse sentido, temos dois aspectos presentes nesse dispositivo e que são também aspectos caros à terapia ocupacional: a heterogeneidade e a produção da diferença.

Se a aposta é na convivência, a potência interventiva se dá na produção de espaços de convívio heterogêneos. Heterogeneidade de gênero, de "diagnóstico", de faixa etária ou de classe econômica das pessoas envolvidas no processo. $\mathrm{O}$ encontro entre sujeitos com diferentes limites e potencialidades possibilita que sejam trabalhadas situaçóes que fazem parte do próprio processo do viver de cada um, no encontro com o outro diferente, a partir das distintas possibilidades de produzir diferenças.

A terapia ocupacional tem invertido a lógica disciplinar e produzido outros caminhos para suas práticas, as quais vêm afirmando o direito à diferença e encontrando positividade em formas de vidas das mais singulares e em situaçóes das mais adversas, a partir do compromisso ético-político do terapeuta ocupacional (LIMA, 2003).

Estamos marcando aqui a afirmaçáo da diferença como um aspecto importante do ponto de vista do compromisso ético-político quando pensamos a interface entre convivência e terapia ocupacional: é a diferença como o motor de um movimento para que se possa diferir (KASTRUP, 2005), afirmando processos intercessores como algo que faz contato para que cada um possa ir além de si mesmo e do outro (DELEUZE; GUATTARI, 1995). Esse exercício 
não se dá para anular as diferenças, mas sim para, ao incluí-las, diminuir as desigualdades e produzir redes afetivas.

No universo das políticas públicas, existem diferentes equipamentos que já possuem uma larga experiência em fazer da convivência um dispositivo central, espaços que, muitas vezes, já contam com as contribuiçôes de terapeutas ocupacionais. Entre esses equipamentos, podemos citar Centros de Convivência e Cooperação, Centros Comunitários, Centros da Juventude, Centros ou Pontos de Cultura, Centros Esportivos, Oficinas comunitárias, Brinquedotecas e outros.

Equipamentos como esses são importantíssimos; no entanto, procuramos afirmar que, no que tange à intervenção terapêutica ocupacional, a convivência como um dispositivo pode estar presente na prática do terapeuta ocupacional em todos os campos de atuação, com todas as populaçôes, independentemente de um equipamento especialmente voltado para esse objetivo.

A promoçáo do encontro efetivo das diferenças e a sua potência em lidar com problemáticas inerentes à vida, habitualmente não podem ser reproduzidas potencialmente em ambientes que segregam, mesmo que não intencionalmente. Assim, faz-se necessário inventar novos espaços, intervir na cidade, produzir açôes em redes que fujam às redes de especialidades, praticar políticas intersetoriais e para além dos setores.

\section{Conclusão}

O texto apresenta algumas correlaçóes entre o conceito de convivência e as práticas interventivas da terapia ocupacional, inclusive possibilitando validar, em um arcabouço teórico, conceitos, caminhos e fazeres já presentes na atuação da área no país.

Para isso, partimos da premissa de que a convivência se dá inicialmente a partir dos encontros possíveis em cada contexto e que a potencializaçấo e a experimentação ativa desses encontros podem ser um objetivo das práticas na terapia ocupacional.

No entanto, ressalta-se que, assim como a não buscamos um padrão ideal de convivência, não se afirmou que um território ou um grupo só terá um espaço de convivência potente se tiver acesso a um terapeuta ocupacional. A convivência pode se dar em qualquer espaço e tempo nos quais se encontrem pessoas com a disponibilidade de com-viver. Nesse diagrama, o terapeuta ocupacional pode funcionar como um elemento agregador, um potencializador de bons encontros para ampliação das possibilidades relacionais, provocando experiências, situaçóes e instaurando novas materialidades possíveis.

Como um rizoma, a convivência pode se estabilizar em torno de uma paróquia, de uma igreja, de um bar, de uma praça. Ela evolui por hastes e fluxos subterrâneos, ao longo de vales fluviais ou de linhas de estradas de ferro (DELEUZE; GUATTARI, 1995). Às vezes, mais próximos da imagem de um rio em constante movimento, e noutras vezes, de uma ferrovia pouco flexível, os espaços de convivência em terapia ocupacional podem se constituir como mais um desses pontos, dessas hastes a partir das quais a convivência agencia um universo de novas conexões, sem fechar-se em si mesma.

Assim, é possível compreender a convivência como dispositivo para a terapia ocupacional a partir das construçóes teóricas e, sobretudo, por diversas experiências empíricas sistematizadas de terapeutas ocupacionais que já evidenciaram a potência intrínseca das práticas de convivência para a produção de redes, de intersetorialidade, de criação de laços sociais e afetivos; a produção de novas experiências e trocas, de movimentos de empoderamento social e de afirmação das diferenças; a produção cultural e a intervenção na cidade (GALLETTI, 2004; LIMA, 2004; LOPES; LEÃO, 2002; FERREIRA; OLIVER, 2010; FERIGATO, 2013).

A afirmação da produção de convivência na diferença é também dizer "sim" à inserção social, à possibilidade de se relacionar com o outro, em resistência à opinião, à neutralidade e à cristalização dessas mesmas relaçóes. Fazer, portanto, da experimentação, um dispositivo, um agenciamento de multiplicidades em relação.

Nessa construção, o sujeito da experiência que trazemos à cena se definiria náo apenas por sua atividade, mas também por sua receptividade (FERRACINI et al., 2014), por sua disponibilidade, por sua abertura para relacionar-se com o outro, para a experimentaçáo do mundo e de si.

\section{Referências}

ALVAREZ, J.; PASSOS, E. Cartografar é habitar um território existencial. In: PASSOS. E.; KASTRUP. V.; ESCÓSSIA. L. (Org.). Pistas do método da cartografia: pesquisa-intervenção e produção de subjetividade. Porto Alegre: Sulina, 2009. p. 131-149.

BORGES, F.; ETLIN, M. Imersôes, reciclagens e singularidades. Boletim do Instituto de Saúde, São Paulo, v. 12, n. 1, p. 94-98, 2010.

BRASIL. Ministério do Desenvolvimento Social e Combate à Fome. Tipificação dos serviços socioassistenciais. Brasília, 2011a. 
BRASIL. Portaria no 3.088, de 23 de dezembro de 2011, que institui a Rede de Atenção Psicossocial para pessoas com sofrimento ou transtorno mental e com necessidades decorrentes do uso de crack, álcool e outras drogas, no âmbito do Sistema Único de Saúde (SUS). Diário Oficial [da] República Federativa do Brasil, Brasília, DF, 26 dez. 2011 b.

BRASIL. Ministério do Desenvolvimento Social e Combate à Fome. Secretaria Nacional de Assistência Social. Departamento de Proteção Social Básica. Concepção de Convivência e Fortalecimento de Vinculos. Brasília, 2013a.

BRASIL. Lei no 12.852 , de 5 de agosto de 2013. Institui o Estatuto da Juventude e dispóe sobre os direitos dos jovens, os princípios e diretrizes das políticas públicas de juventude e o Sistema Nacional de Juventude. Diário Oficial [da] República Federativa do Brasil, Brasília, DF, 6 ago. 2013 b.

DELEUZE, G. O que é um dispositivo? In: DELEUZE, G. O mistério de Ariana. Lisboa: Veja, 1996. p. 83-96.

DELEUZE, G.; GUATTARI, F. Mil Platôs: capitalismo e esquizofrenia. São Paulo: 34, 1995.

EICHELBERGER, M. O que pode a Redução de Danos? Videz-vous de tous vos clichés: o graffiti como produção de saúde. 2012. 74 f. Dissertação (Mestrado em Saúde Coletiva) - Universidade Estadual de Campinas, Campinas, 2012.

ESCÓSSIA, L.; TEDESCO, S. O coletivo de forças como plano de experiência cartográfica. In: PASSOS. E.; KASTRUP. V.; ESCÓSSIA. L. (Org.). Pistas do Método da cartografia: Pesquisa-Intervenção e Produção de Subjetividade. Porto Alegre: Sulina, 2009. p. 92-108.

FABIÃO, E. Performance e teatro: poéticas e políticas da cena contemporânea. Sala Preta, São Paulo, n. 8, p. 235-248, 2008.

FERIGATO, S. Agir criativo em Terapia Ocupacional: uma reflexáo filosófica a partir dos paradoxos da contemporaneidade. Cadernos de Terapia Ocupacional, São Carlos, v. 15, n. 2, p. 131-137, 2007.

FERIGATO, S. Cartografia dos Centros de Convivência de Campinas: produzindo Redes de Encontros. 2013. 320 f. Tese (Doutorado em Saúde Coletiva) - Universidade Estadual de Campinas, Campinas, 2013.

FERRACINI, R. et al. Uma experiência de cartografia territorial do corpo em arte. Urdimento, Florianópolis, v. 1, n. 22, p. 219-232, 2014.

FERREIRA, T. G.; OLIVER, F. C. A atenção domiciliar. Revista de Terapia Ocupacional da Universidade de São Paulo, São Paulo, v. 21, n. 3, p. 189-197, 2010.

FOUCAULT, M. O que é o Iluminismo. In: ESCOBAR, C. H. (Org.). Michel Foucault (1926-1984) - o Dossier - últimas entrevistas. Rio de Janeiro: Taurus, 1984. p. 103-112.

FOUCAULT, M. Microfísica do poder. Rio de Janeiro: Graal, 1992.
FURTADO, E. A.; MARCONDES, J. L. Atividade sagrada pelo Método da Escavaçáo. Cadernos de Terapia Ocupacional da UFSCar, São Carlos, v. 21, n. 3, p. 653661, 2013.

GALHEIGO, S. M. O cotidiano na terapia ocupacional: cultura, subjetividade e contexto histórico-social. Revista de Terapia Ocupacional da Universidade de São Paulo, São Paulo, v. 14, n. 3, p. 104-109, 2003.

GALLETTI, M. C. Oficina em saúde mental: instrumento terapêutico ou intercessor clínico? Goiânia: UCG, 2004.

GUATTARI, F. Caosmose: um novo paradigma estético. São Paulo: 34, 2006.

GUATTARI, F.; ROLNIK, S. Micropolitica: cartografias do desejo. Petrópolis: Vozes, 1986.

HARDT, M.; NEGRI, A. Multidão: guerra e democracia na era do Império. Rio de Janeiro: Record, 2012.

INFOPÉDIA. Lingua Portuguesa com acordo ortográfico. Porto: Porto Editora, 2015. Disponível em: <http:// www.infopedia.pt/dicionarios/lingua-portuguesa/convivência>. Acesso em: 6 jun. 2015.

INTERNATIONAL SOCIETY OF OCCUPATIONAL SCIENCE - ISOS. Disponível em: <http://www. isoccsci.org/>. Acesso em: 25 mar. 2013.

KASTRUP, V. Políticas cognitivas na formação do professor e o problema do devir-mestre. Educaçâo e Sociedade, Campinas, v. 26, n. 93, p. 1273-1288, 2005.

LIMA, E. M. F. A. Desejando a diferença: consideraçóes acerca das relaçóes entre os terapeutas ocupacionais e as populaçóes tradicionalmente atendidas por estes profissionais. Revista de Terapia Ocupacional da Universidade de São Paulo, São Paulo, v. 14, n. 2, p. 64-71, 2003.

LIMA, E. M. F. A. Oficinas, laboratórios, ateliês, grupos de atividades: Dispositivos para uma clínica atravessada pela criação. In: COSTA, C. M.; FIGUEIREDO A. C. Oficinas terapêuticas em saúde mental: sujeito, produção e cidadania. Rio de Janeiro: Contra Capa, 2004. p. 59-81.

LIMA, E. M. F. A.; ARAGON, L. E. Agenciamento coletivo de clínica: conceitos se fazendo nos encontros. In: LIMA, E. M. F. A.; FERREIRA NETO, J. L.; ARAGON, L. E. Subjetividade contemporânea: desafios teóricos e metodológicos. Curitiba: CRV, 2010. p. 129-148.

LIMA, E. M. F. A.; OKUMA, D. G.; PASTORE, M. N. Atividade, ação, fazer e ocupação: a discussão dos termos na Terapia Ocupacional brasileira. Cadernos de Terapia Ocupacional da UFSCar, São Carlos, v. 21, n. 2, p. 243-254, 2013.

LOPES, R. E.; LEÃO, A. Terapeutas Ocupacionais e Centros de Convivência e cooperativas: novas açóes em saúde. Revista de Terapia Ocupacional da Universidade de São Paulo, São Paulo, v. 13, n. 2, p. 56-63, 2002.

MAGALHÃES, L. Ocupação e atividade: tendências e tensôes conceituais na literatura anglófona da terapia 
ocupacional e da ciência ocupacional. Cadernos de Terapia Ocupacional da UFSCar, São Carlos, v. 21, n. 2, p. 255-263, 2013.

MARTORELL, M. F. Antropología de la convivência. Manifesto de Antropologia urbana. Barcelona: Catedra, 1997.

MEDEIROS, M. H. R. Terapia Ocupacional: um enfoque epistemológico e social. Sáo Carlos: EdUFSCar, 2010.

PELBART, P. P. Vida capital. Ensaios sobre biopolítica. São Paulo: Iluminuras, 2003.

QUARENTEI, M. S. Terapia Ocupacional e produção de vida. In: CONGRESSO BRASILEIRO DE TERAPIA OCUPACIONAL, 7., 2001, Porto Alegre. Anais... Porto Alegre: ABRATO, 2001. p. 1-3. CD-ROOM.

SILVA, C. R. As atividades como recurso para pesquisa. Cadernos de Terapia Ocupacional da UFSCar, São Carlos, v. 21, n. 3, p. 461-470, 2013.
SPINOZA, B. Ética. Belo Horizonte: Autêntica, 2008.

TEIXEIRA, R. R. As redes de trabalho afetivo e a contribuição da saúde para a emergência de uma outra concepção de público. In: RESEARCH CONFERENCE ON: RETHINKING “THE PUBLIC” IN PUBLIC HEALTH: NEOLIBERALISM, STRUCTURAL VIOLENCE, AND EPIDEMICS OF INEQUALITY IN LATIN AMÉRICA, 2004, San Diego. Anais... San Diego: Center for Iberian and Latin American Studies, University of California-San Diego, 2004. Disponível em: <http://www.corposem.org/rizoma/redeafetiva.htm>. Acesso em: 20 jul. 2016.

UNIVERSIDADE DE SÃO PAULO - USP. Definição de Terapia Ocupacional. São Paulo, 1997.

WEINMANN, A. O. Dispositivo: um solo para a subjetivação. Revista Psicologia \& Sociedade, Belo Horizonte, v. 18, n. 3, p. 16-22, 2006.

\section{Contribuição dos Autores}

Sabrina Helena Ferigato foi responsável pela concepção e estruturação do texto. Carla Regina Silva e Gerusa Ferreira Lourenço foram responsáveis por contribuiçóes ao texto e realizaram a revisão do texto. Todas as autoras aprovaram a versão final do texto.

\section{Notas}

${ }^{1}$ Para Spinoza, "corpos” são sistemas relacionais abertos, altamente suscetíveis e cambiantes, um grupo infinito de partículas relacionando-se por paragem e movimento, e que tem essencialmente o poder de afetar e ser afetado. Os corpos humanos ou inumanos são vias, são meios, e não um estado de coisa. Dessa maneira, o corpo é definido pelos afetos de que é capaz de gerar, gerir, receber e trocar (FABIÃO, 2008)

${ }^{2}$ De acordo com a Sociedade Internacional de Ciência Ocupacional, "ocupação” refere-se a todas as atividades que ocupam o tempo das pessoas e dão sentido a suas vidas (INTERNATIONAL..., 2013).

${ }^{3}$ Corpo em Spinoza (2008): enquanto seres individuados e finitos, somos compostos por partículas infinitamente pequenas, agrupadas em conjuntos infinitos, que, em uma dada relação, nos caracterizam. Composiçôes extensivas fazem-se e se desfazem a todo o momento, marcadas por seus movimentos e repousos, lentidóes e velocidades. 